\title{
Development of Taekwondo Skill Test for Sub Junior Boys
}

\author{
Harmanpreet Kaur, Pradeep Kumar Baldeena
}

\begin{abstract}
In the field of taekwondo only few skills available to evaluate the skill performance of taekwondo players. So researcher has undertaken the study "Development of taekwondo skill test for sub junior boys". The purpose of the study was in the development of taekwondo skill test for selection, evaluation and assessment of performance of taekwondo, the normative study was conducted under descriptive research. The study was confined to age group 12 to 13 years' school level male taekwondo players from northern India. The researcher used purposive random sampling method. Standard procedures were followed to conduct this research. The researcher followed step-wise method of construction and establishing standard norms. The researcher analyzed important basic skills used by school level taekwondo of age group 12 to 13 years to help the experts from the taekwondo field by face validity. The newly designed skill test was administered on school level male taekwondo of age group 12 to 13 years from various taekwondo clubs, different schools and practice houses in northern India and the test was revised. After the modification the test was finalized and changes were made Validity, Reliability and Objectivity were established by following procedure given in various books of tests, measurement and evaluation.
\end{abstract}

The data, which was collected by administering tests, were statistically treated to develop norms for all the test items. The normative scales, namely, the Percentile Scale and 7 Sigma Scale were constructed for the male taekwondo of state and national level. The norms were constructed by using Percentile and 7 Sigma Scale techniques analyzed through statistical packages, the scores were further classified into five grades i.e. Excellent, Good, Average, Fair, Poor under Normal Distribution.

Keywords : Taekwondo, Test, Standardization, Norms.

\section{INTRODUCTION}

The Taekwondo is an Olympic sport. Tae" meaning foot, "Kwon" meaning fist and "Do" meaning way of. So, literally Taekwondo means "the way of the foot and fist". The dynamic movements and their proper execution in playing situations are entirely scientific and bio-mechanical principles are fully employed in taekwondo. Taekwondo requires a high degree of skill development, physical fitness and motor abilities for outstanding performance the frequent change and advancement in wrestling game are mainly due to the overemphasis given by sports experts in terms of

Revised Manuscript Received on July 22, 2019.

Harmanpreet Kaur,

Associate Professor, School of Physical Education, Lovely Professional University, Punjab (India).

Pradeep Kumar' Baldeena, Research Scholar, Lovely Professional University, Punjab (India) systematic training and accurate application of scientific knowledge. A skill test may serve as useful tools for the selection of real Taekwondo for a team representing their institutions, district or state association on an objective basis minimizing bias on the part of selection committee members Fundamental movement and sports skills comprising agility, balance, coordination, and running, jumping, throwing, kicking and catching are the foundation of all the sports. Children who are interested to be a sports person and want to win the Olympic medals must be improved in these skills before the beginning of their growth spurt in youth. Without the experienced in the basic movement skills a person will have complexities to take part in a selected game and will have less chance for sports success and lifelong fulfillment of bodily activity. The best time of skill training takes place for boys between the ages of nine and twelve years. During this time sportsperson should be developing the basic fundamental movements and major sports skill which is the base of any sports. Capability in these skills, builds it simple for a sportsperson to become skilled and shine in choosing sports such as taekwondo. Taekwondo, loosely translated as "way of the fist and foot" most popular among various martial art. Taekwondo established in Korea in 1973 is a popular and extremely speedy Olympic event among martial arts. 204 National associations are the member of The World Taekwondo Federation. The role of the National member association has been remarkable for making Taekwondo one of the famous sports in the world. In the Sydney Olympic in 2000 in the Australia Taekwondo included first time as the medal sports. World Taekwondo federation policy continuously improving the standard of Taekwondo worldwide as a result the strength of Taekwondo practitioners achieves approximately 70 million globally. The frequent change and advancement in Taekwondo game are mainly due to the overemphasis given by sports experts in terms of systematic training and accurate application of scientific knowledge. The recent study's conclusion of lee Jeong Dae, Todd Gilson, Yi Bong (2013) concluded that The Kukkiwon, the technical head quarter of the world Taekwondo Federation. Which is responsible for developing right values of Taekwondo and excavating new values related to it to train promising Taekwondo instructors, but Kukkiwon has recently been criticized for not playing such a role successfully. 


\section{MATERIAL AND METHOD}

The purpose of this study was to construct and standardized the norms for evaluating the skill performance of players in Taekwondo Skill Test. Since, there is a lack of standardized evaluative criteria in Taekwondo for assessing the ability, grading and predicting the performance of Taekwondo players, an effort was undertaken to construct and standardized Norms for Skill Test for 12 to 13 years Taekwondo Players. For this purpose 60 male, district, state and national level Taekwondo players of different states in India were randomly selected to serve as subjects. The performance of Taekwondo players in the Taekwondo test battery of five test items, Namely, Punch, Dollyo, Dwit chagi (Back Kick), Axe Kick, Tornado Kick was chosen for the purpose of the study and to construct a skill test. The data was collected by administering the test for the selected test items during open and school district, state, and national Taekwondo championship. The data, which was collected by administering tests, was statistically treated to develop norms for all the test items. The normative scales, namely, the Percentile Scale and 7 Sigma Scale were constructed for the Male Taekwondo players of state and national level. The norms were constructed by using Percentile and 7 Sigma Scale techniques analyzed through statistical packages, the scores were further classified into seven grades i.e. Outstanding, Brilliant, Superior, Good, Average, Fair, under Normal Distribution. The subjects were explained about the various test items before conducting the test in which they had to participate. To facilitate the best effort from the subject's assistance from professionally qualified.

Development of Taekwondo Skill Test for sub Junior Boys Taekwondo coach and the physical education teacher of the respective schools was required and the investigator trained them physically to collect data perfectly before the data collection. With the intention of making the study more reliable the researcher educated the Taekwondo about the performance of the skill test and also explained the benefits of the skill test concerned with their performance. The investigator assured them, that this test would provide the best information about the level of their Taekwondo which would help them to improve their achievements for the forthcoming Taekwondo competitions.

\section{A. Scoring}

The scoring was based on expert's vision. Three experts gave the marks to perform on the scale of 1-5 and assign points according to the perfection of skill. The experts then compared the scoring of four variables, i.e. grip, stance, speed/timing and taekwondo skill. During the whole course of processing the opponent remained stagnancies. Three trials were given to the performer and best was recorded. There was no time bond, but the performer was directed to perform the skill quickly. The skill was noticed by the three judges. They scored independently than the three different scores were added, mean was calculated and final scoring was done.

\section{Scoring Table}

1. GRIP 54321

2. STANCE 54321

3. TIMING/SPEED 54321

4. TAEKWONDO SKILLS. 54321

5 POINTS EXCELLENT

4 POINTS. GOOD

3 POINTS. AVERAGE

2 POINTS. FAILURE

1 POINT POOR

These steps are as follows:

1. Selecting a criterion

2. Developing experimental test items

3. Computing validity, reliability and objectivity.

4. Establishing norms

\section{RESULT}

The result of reliability as presented in the table indicate that the reliability coefficient of the items comprising Middle Punch Test, Dollyo Chagi (Turning Kick) Test, Dwit Chagi (Back Kick) Test, Naeryo Chagi (Axe Kick) Test, and Bandae Dollyo (Tornado Kick) Test in the newly formed test for 12 to 13 years age group were $0.47,0.53,0.71,0.67$, and 0.20 respectively. The reliability coefficients for all the selected age groups were statistically significant.

Thus test re-test reliability coefficients indicate that the Taekwondo skill test has got its preliminary form for the selected male Taekwondo players.

The result presented in the table revealed that all the dimensions of the preliminary form of the Taekwondo skill test have significant reliability coefficients $(p<0.05)$ so this scale got its primary form shows that the maximum scores of Taekwondo skill Test battery for 12 to 13 years male Taekwondo players are at the 100th percentile and the minimum score are at the 5th percentile for age group 12 to 13 years male Taekwondo player's. The lowest scores are at the top while the highest scores are at the bottom of the table.

\section{TABLE 1: RELIABILITY OF THE}

\section{TAEKWONDO SKILL TEST}

\begin{tabular}{|cc||c||l|}
\hline SR.N & \multicolumn{1}{||}{ O } & TEST OF ITEMS & "r" \\
\hline 1. & Middle Punch Test & 0.47 \\
2. & Dollyo Chagi (Turning Kick)Test & 0.53 \\
3. & Dwit Chagi (Back Kick)Test & 0.71 \\
4. & Naeryo Chagi (Axe Kick)Test & 0.67 \\
5. & Bandae Dollyo (Tornado Kick)Test & 0.20 \\
\hline
\end{tabular}

The result is significant at $<0.05$ 
TABLE 2: RELIABILITY OF THE TOTAL

TAEKWONDO SKILL TEST BATTERY

\begin{tabular}{|c|l|l|}
\hline SR.NO. & $\begin{array}{l}\text { TEST } \\
\text { BATTERY }\end{array}$ & "r" \\
\hline $\mathbf{1}$ & $\begin{array}{l}\text { Taekwondo skill } \\
\text { test }\end{array}$ & $\mathbf{0 . 5}$ \\
\hline
\end{tabular}

The $\mathrm{P}$ value is 4.7E-05. The result is significant at $<0.05$.

\section{PERCENTILE NORMS}

Percentile norms for the Taekwondo Players with their age group years have been presented as follows

TABLE 3: PERCENTILE NORMS OF TAEKWONDO SKILL TEST BATTERY FOR 12 TO 13 YEARS MALE TAEKWONDO PLAYERS

\begin{tabular}{|c||c||c||c|c||c|c|}
\hline $\begin{array}{c}\text { PERCEN- } \\
\text { TILES }\end{array}$ & PUNCH & DOLLYO & $\begin{array}{c}\text { DWIT } \\
\text { CHAGI }\end{array}$ & $\begin{array}{c}\text { AXE } \\
\text { KICK }\end{array}$ & $\begin{array}{c}\text { TORN- } \\
\text { ADO } \\
\text { KICK }\end{array}$ & $\begin{array}{c}\text { TOTAL } \\
\text { SKILL } \\
\text { SCORE }\end{array}$ \\
\hline 5 & 4.00 & 4.00 & 6.00 & 10.65 & 9.00 & 40.00 \\
10 & 4.00 & 5.00 & 8.00 & 12.00 & 12.00 & 43.00 \\
15 & 5.00 & 5.00 & 8.00 & 12.00 & 12.00 & 47.00 \\
20 & 6.00 & 6.00 & 10.00 & 15.00 & 16.00 & 50.00 \\
25 & 6.00 & 6.00 & 10.00 & 15.00 & 16.00 & 54.00 \\
30 & 6.00 & 6.00 & 12.00 & 18.00 & 16.00 & 59.00 \\
35 & 7.00 & 6.00 & 12.00 & 18.00 & 20.00 & 64.00 \\
40 & 7.00 & 6.00 & 12.00 & 18.00 & 20.00 & 67.00 \\
45 & 7.00 & 7.00 & 12.00 & 18.00 & 24.00 & 69.00 \\
50 & 7.00 & 7.00 & 12.00 & 18.00 & 24.00 & 71.00 \\
55 & 7.00 & 7.00 & 14.00 & 21.00 & 24.00 & 72.00 \\
60 & 7.00 & 7.00 & 14.00 & 21.00 & 24.00 & 74.00 \\
65 & 8.00 & 7.00 & 14.00 & 21.00 & 28.00 & 75.00 \\
70 & 8.00 & 7.00 & 14.00 & 21.00 & 28.00 & 76.00 \\
75 & 8.00 & 8.00 & 14.00 & 21.00 & 28.00 & 78.00 \\
80 & 8.00 & 8.00 & 14.00 & 24.00 & 28.00 & 79.00 \\
85 & 8.00 & 8.00 & 16.00 & 24.00 & 28.00 & 81.00 \\
90 & 8.00 & 8.00 & 16.00 & 24.00 & 32.00 & 83.00 \\
95 & 8.00 & 8.00 & 16.00 & 24.00 & 32.00 & 87.00 \\
100 & 9.00 & 9.00 & 18.00 & 27.00 & 36.00 & 94.00 \\
\hline
\end{tabular}

TABLE 4: 7 POINT STANDARD SCALE FOR

EVALUATION OF 12-13 YEARS AGE GROUPS (PUNCH TEST)

\begin{tabular}{|c|c|}
\hline $\begin{array}{c}\text { 7 POINT STANDARD } \\
\text { SCALE }\end{array}$ & $\begin{array}{c}\text { SCORE RANGE } \\
\text { FOR } 12 \text {-13 } \\
\text { AGE GROUP FOR } \\
\text { PUNCH }\end{array}$ \\
\hline OUTSTANDIN & 9.91 TO 11.16 \\
G & 8.64 TO 9.90 \\
BRILLIANT & 7.39 TO 8.63 \\
SUPERIOR & 6.13 TO 7.38 \\
GOOD & 4.87 TO 6.12 \\
AVERAGE & 3.61 TO 4.86 \\
FAIR & 2.37 TO 3.60 \\
POOR & \\
\hline
\end{tabular}

\section{REFERENCES}

1. AAHPER (1969) skill test manual volleyball. American Alliance for Health,

2. Physical Education and Recreation Washington D.C

3. Barrow, H. M., \& Mc Gee, R. (1979). A practical approach to measurement in

4. physical education. Henry Kempton Publishers. London

5. Bhattacharyya. \& Bhattacharya, A. (1977).Evaluation And Measurement in

6. Education .Calcutta: Blacki (India) Employees Cooperative Industrial society Ltd. 